\title{
Development of laser welding of high strength aluminium alloy 2024-T4 with controlled thermal cycle
}

\author{
Mete Demirorer ${ }^{1}$, Wojciech Suder ${ }^{1, *}$, Supriyo Ganguly ${ }^{1, *}$, Simon Hogg, ${ }^{2,}$, and Hassam Naeem ${ }^{2}$ \\ ${ }^{1}$ Welding Engineering and Laser Processing Centre, Cranfield University - United Kingdom \\ ${ }^{2}$ Department of Materials, Loughborough University - United Kingdom
}

\begin{abstract}
An innovative process design, to avoid thermal degradation during autogenous fusion welding of high strength AA 2024-T4 alloy, based on laser beam welding, is being developed. A series of instrumented laser welds in $2 \mathrm{~mm}$ thick AA 2024-T4 alloys were made with different processing conditions resulting in different thermal profiles and cooling rates. The welds were examined under SEM, TEM and LOM, and subjected to micro-hardness examination. This allowed us to understand the influence of cooling rate, peak temperature, and thermal cycle on the growth of precipitates, and related degradation in the weld and heat affected area, evident as softening. Although laser beam welding allows significant reduction of heat input, and higher cooling rates, as compared to other high heat input welding processes, this was found insufficient to completely supress coarsening of precipitate in HAZ. To understand the required range of thermal cycles, additional dilatometry tests were carried out using the same base material to understand the timetemperature relationship of precipitate formation. The results were used to design a novel laser welding process with enhanced cooling, such as with copper backing bar and cryogenic cooling.
\end{abstract}

\section{Introduction}

Aluminium $(\mathrm{Al})$ is most commonly preferred due to its superior features, such as strength-to-weight ratio, high formability, high durability, corrosion resistance with remarkable cost-efficiency, manufacturability and abundance (Miller et al., 2000; Fridlyander et al., 2002; Sakurai, 2008; Hong and Shin, 2017). There is a growing body of interest that recognises the importance of aluminium processing and its strengthening procedures. The standard features of aluminium can be advanced through some heat treatments, such as age-hardening (Oguz, 1990; Jordan, 2016; Andersen et al., 2018). On the other hand, aluminium alloys are very sensitive to their processing conditions (Nascente et al., 2002) in spite of the fact that these hardening processes provide advantageous properties through generating secondary phases, i.e. precipitates, in the matrix, which create internal stresses by inhibiting dislocation motion which is required for the plastic deformation. Obstacles to the deformation provides to increase the hardness and strength rates crucially (Ambriz and Jaramillo, 2014).

In accordance with results from literature (SánchezAmaya et al., 2012; Alshaer, Li and Mistry, 2017; Niu et al., 2017; Ahn et al., 2018) about aluminium welding, previous studies generally focus on problems which occur in fusion zone (FZ), and research to date has not yet determined how the coarsening of precipitates can be inhibited in the over-aged zone, i.e. heat-affected zone

\footnotetext{
* Corresponding author: w.j.suder@cranfield.ac.uk

* Corresponding author: s.ganguly@cranfield.ac.uk

* Corresponding author: S.C.Hogg@1boro.ac.uk
}

(HAZ). As mentioned above, these secondary phases are susceptible to the heat which has a primary role during welding (Zhang et al., 2015). In addition to other problems like hot cracking, porosity etc., softening related to negative precipitate evolution is inevitable upon welding of aluminium alloys. Generally, welding of age hardenable aluminium alloys is avoided because of the sensitivity of these secondary phases to the heat of welding, which results in coarsening of the precipitates in HAZ (Zervaki and Haidemenopoulos, 2007; Zhang et al., 2016). Arora et al. (2010) also give essential information about the peak temperature interval of HAZ of welded 2219 aluminium alloy and HAZ usually occurred between $400{ }^{\circ} \mathrm{C}$ and $150{ }^{\circ} \mathrm{C}$. Mishra and Sidhar (2017) identified that $1 \mathrm{~s}-2 \mathrm{~s}$ is enough to make the precipitates in $2 \times x x$ aluminium alloys coarsened in higher temperature rates. When we consider this information, and examine the TTP diagrams of $2 \mathrm{xxx}$ aluminium alloys, it seems that critical average cooling rate should be higher than $250{ }^{\circ} \mathrm{C} / \mathrm{s}$ to prevent harmful precipitation coarsening in $\mathrm{HAZ}$, between the temperature intervals from $400{ }^{\circ} \mathrm{C}$ to $150^{\circ} \mathrm{C}$.

It makes the aluminium welding process challenging. Although these problems - which occur because of heat retention - can be reduced through generating novel design, considering the process characteristics and dynamics. This novel design should aim to mitigate HAZ softening. 


\section{Experimental Setup}

To understand what thermal cycle is needed to mitigate/minimise HAZ softening, a range of experiments were performed, altering the parameters to vary thermal welding cycles. The effect of thermal cycling on the microstructural evolution and related mechanical properties was assessed and it was supported by light optical microscope (LOM) and secondary electron microscope (SEM) analyses.

\subsection{Welding Equipment}

Diode-pumped continuous wave $(1.070 \mu \mathrm{m})$ IPG YLR ytterbium fibre laser with $8 \mathrm{~kW}$ of maximum power was used in these experiments, as seen by the setup found in Figure 1. To achieve a $0.6 \mathrm{~mm}$ beam diameter, $24.3 \mathrm{~cm}$ focal length was set between the baseplate and the lens. The angle between the laser beam and the base plate was set to $5^{\circ}$ to protect the laser equipment against reflection.

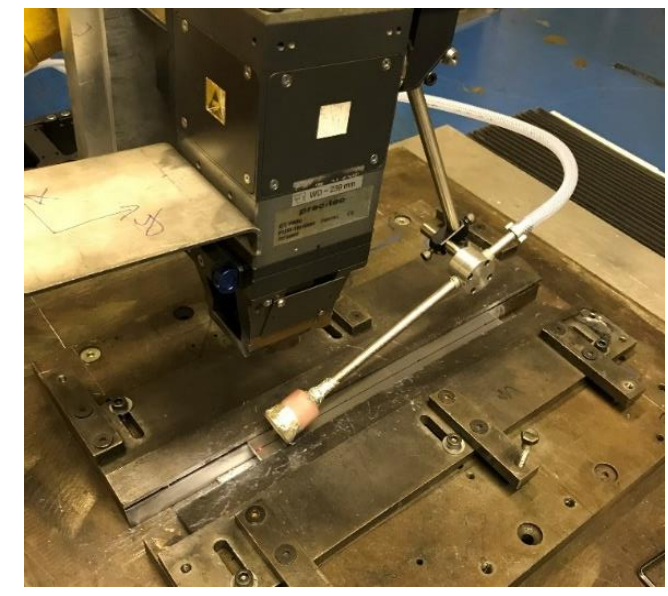

Fig. 1. Experimental setup.

To assess the effect of passive cooling during laser welding, a copper backing bar was added to the jig as a heat sink, which is shown schematically in Figure 2, and it was tried to increase the cooling rate by passive cooling. Thermocouple measurements recorded change in the thermal cycle. Average cooling rates in HAZ were calculated using Equation 1 between the temperature rates of $400{ }^{\circ} \mathrm{C}$ and $150{ }^{\circ} \mathrm{C}$, which are dangerous for harmful precipitate evolution, which results in HAZ softening. The active cooling rate to mitigate HAZ softening, was decided.

Average Cooling Rate $\left[{ }^{\circ} \mathrm{C} / \mathrm{s}\right]=\left(400^{\circ} \mathrm{C}-150^{\circ} \mathrm{C}\right] / \Delta$ Time $[\mathrm{s}]$

Table 1. Composition of material.

\begin{tabular}{|c|c|c|c|c|c|}
\hline \multicolumn{6}{|c|}{ Substrate (AA 2024-T4), \% } \\
\hline Al & Ref & Cu & 4.30 & $\mathbf{C r}$ & 0.03 \\
\hline Si & 0.06 & Mn & 0.52 & $\mathbf{Z n}$ & 0.18 \\
\hline Fe & 0.10 & Mg & 1.50 & $\mathbf{T i}$ & 0.004 \\
\hline
\end{tabular}

Heat Input $[\mathrm{kJ} / \mathrm{m}]=$ Power $[\mathrm{kW}] /$ Speed $[\mathrm{m} / \mathrm{s}]$

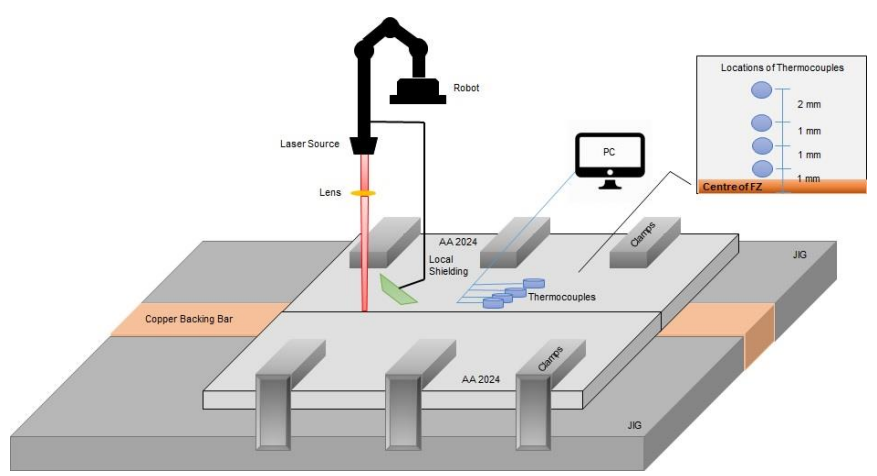

Fig. 2. Schema of the copper bar added laser fixture.

\subsection{Welded Materials and Parameters}

During the experiments, $2 \mathrm{~mm}$ thick AA 2024 alloys in T4 condition were used, and the composition of AA 2024-T4 alloys used can be found in Table 1. Parameters which were used in the experiments can be found in Table 2. Heat input rates were calculated by using Equation 2.

Table 2. Parameters used in laser welding experiments.

\begin{tabular}{|c|c|c|c|c|l|}
\hline & $\begin{array}{l}\text { Power } \\
\mathbf{P},[\mathbf{W}]\end{array}$ & $\begin{array}{l}\text { Power } \\
\mathbf{P},[\mathbf{k W}]\end{array}$ & $\begin{array}{l}\text { Speed V, } \\
{[\mathbf{c m} / \mathbf{m i n}]}\end{array}$ & $\begin{array}{l}\text { Speed } \\
\mathbf{V},[\mathbf{m} / \mathbf{s}]\end{array}$ & $\begin{array}{l}\text { Heat } \\
\text { Input } \\
{[\mathbf{k J} / \mathbf{m}]}\end{array}$ \\
\hline 1 & 2500 & 2.5 & 100 & 0.017 & 150.00 \\
\hline 2 & 8000 & 8.0 & 1000 & 0.167 & 48.00 \\
\hline
\end{tabular}

\subsection{Analysing Data}

\subsubsection{Macro- and Microstructural Analysis}

After performing the laser welding experiments, samples were cut and mounted by casting the pieces of samples into the resin. When the cold mounting was completed, samples were ground by using silicon carbide abrasive papers from coarse $\mathrm{P} 240 \mathrm{~g}$, fine $\mathrm{P} 1200 \mathrm{~g}$ and finer P2500g. After grinding, samples were polished with the chemo-textile clothes with using $6 \mu \mathrm{m}$ and $9 \mu \mathrm{m}$ diamond abrasives suspensions, and at the final stage, samples were polished with $0.05 \mu \mathrm{m}$ OP-S colloidal silica suspension. Finally, samples were etched with Keller's reagent. Afterwards, macro- and micro-images were examined by using LOM and SEM to show and compare the precipitate coarsening with varying the various heat input rates. SEM of Oxford Instruments was used to understand the characteristics of the selected areas of the specimen and to figure out the precipitate coarsening as microstructural analysis in this study.

\subsubsection{Hardness Testing}

To investigate the change in the mechanical properties, hardness mapping was conducted using the Zwick/Roell ZHV hardness machine in the facilities of the Cranfield University. The load of the indentations was $100 \mathrm{~g}$ and dwell time was $15 \mathrm{~s}$. Hardness mapping was performed $0.05 \mathrm{~mm}$ below the top surface of the weldment, and the 
distance between two indentations was $0.5 \mathrm{~mm}$. The first indentation was made into the centre of fusion zone, and 39 indentations were made during the mapping of the weld profile.

\subsection{Finite Elements Modelling (FEM)}

FEM model was developed on ABAQUS software to simulate the laser welding process. The domain was meshed as seen in Figure 3. Figure 4 shows that the region which was affected by the heat of welding. It was meshed densely, but unaffected areas were meshed coarsely. This model contains 3D volume elements with eight nodes (C3D8T) to make coupled temperaturedisplacement numerical analysis of heat distribution, and 8800 elements were generated on the domain.

Transient heat transfer analysis was conducted to obtain thermal cycle and to calculate the cooling rate. Moving Gaussian heat source was used by using a DFLUX subroutine, which was programmed using FORTRAN (Tsirkas, Papanikos and Kermanidis, 2003), and it was used with the generated model while loading the conditions.

User-defined surface heat flux which was managed by the DFLUX subroutine - which was used to simulate the laser welding process, and power-travel speed variables were changed in this DFLUX subroutine.
Material properties were taken from the studies of Zhao et al. (2012). $5.67 \times 10-8 \mathrm{Wm}^{2} / \mathrm{K}^{4}$ as Stefan-Boltzmann constant and -273.15 as absolute zero temperature to obtain results in degrees Celsius were set in the model creation stage.

Experimental data were used to validate this FEM model. The increased cooling rate provided by active cooling was simulated, as seen in Figure 5. The simulated cooling rate was enough to exhibit HAZ softening and provide a remarkable clue for developing novel design by including the active cooling method.

Thermal profile and cooling rate of FEM were presented and compared with the results which were obtained from laser only welding simulations. Boundary condition was implemented into this numerical model.

The surface of the plate, except the region where the laser was applied, was fixed to $5{ }^{\circ} \mathrm{C}$. This boundary condition represents the cryogenically cooled surface. It was supposed that the temperature at the top surface of the substrate will drop into the pre-defined lower temperature $\left(5^{\circ} \mathrm{C}\right)$ through using of cryogenic gas.

The boundary conditions were initialised during the welding step to prevent the substrate from pre-cooling. A pre-cooled substrate will not melt.

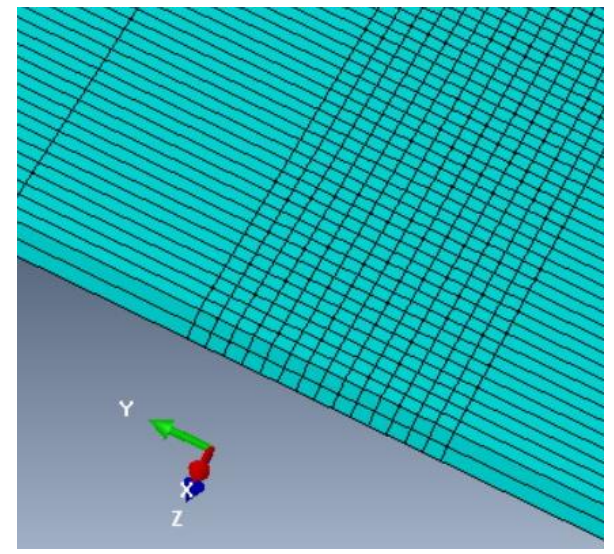

Fig 4. Coarse and dense mesh on the modelled part.
Fig 3. FEM model generated on ABAQUS software

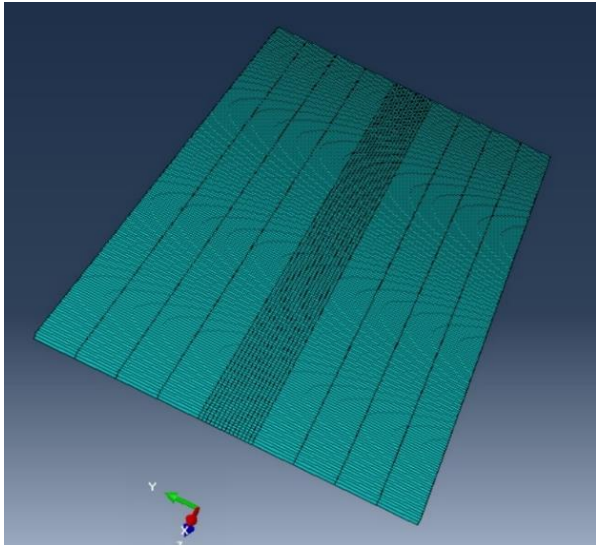

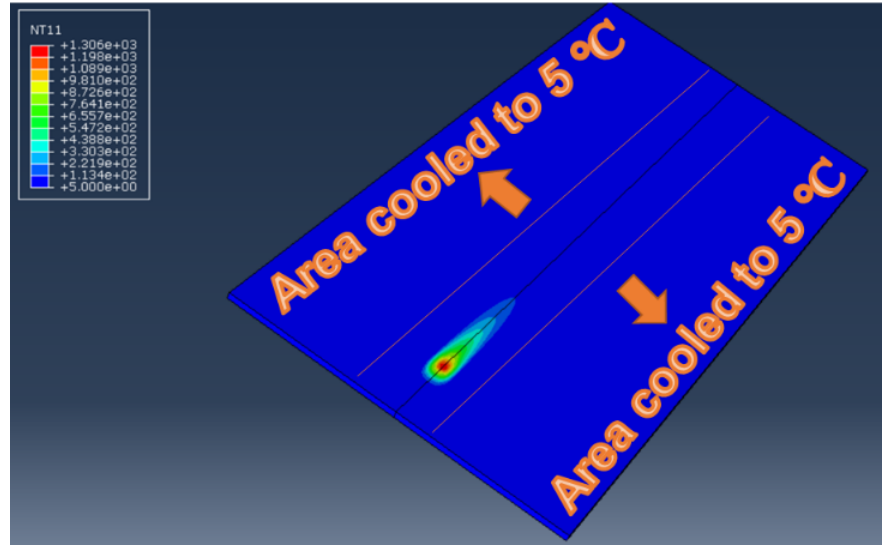

Fig 5. Model representing cryogenic cooling 


\section{Methodology}

A systematic literature review was conducted of studies regarding how age-hardenable aluminium alloys lose their advanced properties during welding processes, and how much cooling rate is required to mitigate HAZ softening in welded structures. It was found from Arora et al. (2010) and Mishra and Sidhar (2017) that processing temperatures between $400{ }^{\circ} \mathrm{C}$ and $150{ }^{\circ} \mathrm{C}$ are very critical, and the exposure to these temperatures for more than $1 \mathrm{~s}$ or $2 \mathrm{~s}$ causes disadvantageous precipitate coarsening. Therefore, it must be noted that the average cooling rate must be more than $250{ }^{\circ} \mathrm{C} / \mathrm{s}$. A series of welds was achieved with varying thermal cycles and its effect on resulting microstructure and properties assessed. Comparison between the data from literature and experiments was made. The outcome was used to derive a range of possible cooling rates to mitigate HAZ softening offered by standard laser processing, which includes beneficial instrumentations to reduce side effects of the heat of welding process. FEM on ABAQUS software was used to simulate laser only welding process, and to establish if the experimentally obtained cooling rate was enough to inhibit HAZ softening. At the last stage, it was checked which cooling rates are feasible with standard laser welding process and with enhanced cooled ones.

\section{Results and Discussion}

\subsection{Thermal Analysis}

Heat input rate changes the cooling rate and peak temperature exposure. It was revealed in Figure 6, which was obtained at the distance of $1 \mathrm{~mm}$ from the centre of FZ that using the higher heat input rate $(150 \mathrm{~kJ} / \mathrm{m})$ during laser processing causes decreased cooling rate. Still, lower heat input $(48 \mathrm{~kJ} / \mathrm{m})$ provides a higher cooling rate. It means that temperature drops in shorter times in the lower heat input laser welding processing. Hence, narrower weld profiles can be obtained by achieving small HAZ.

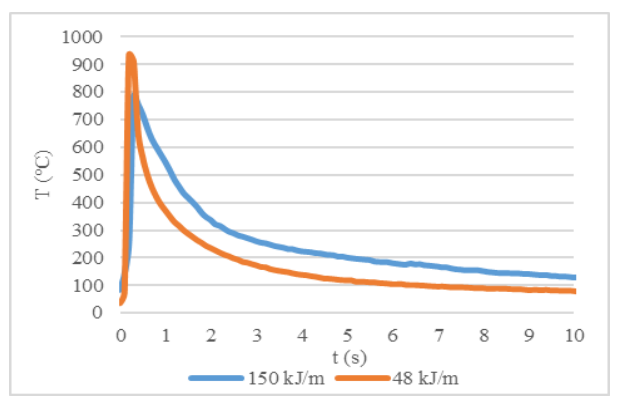

Fig 6. Thermal cycle of lower and higher heat input rates.

As the cooling rate between processing temperatures of $400{ }^{\circ} \mathrm{C}$ and $150{ }^{\circ} \mathrm{C}$ is very critical, possible cooling rates in $\mathrm{HAZ}$ of standard laser welding and copper cooled one were measured and illustrated in Figure 7.

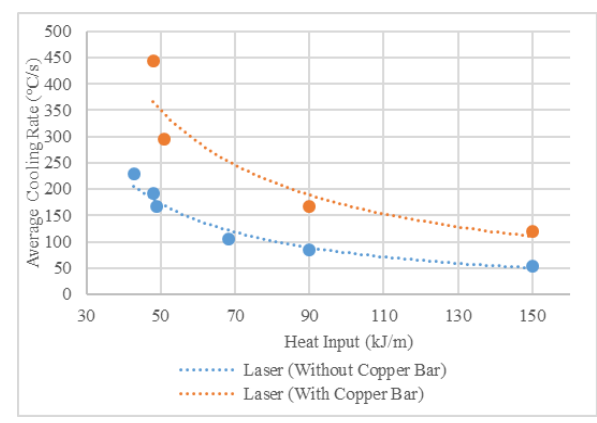

Fig 7. Changing in the average cooling rate in HAZ with alteration of heat input of various processes.

As seen in Figure 7, the application of higher heat input rate of laser only welding causes $55^{\circ} \mathrm{C} / \mathrm{s}$ as the average cooling rate in $\mathrm{HAZ}$, but lower heat input rate provides $192{ }^{\circ} \mathrm{C} / \mathrm{s}$ average cooling rates in HAZ. However, it is crucial to say that using a copper bar as heat sink increases the cooling rate remarkably in the heat-affected zone. Higher heat input rate with using the copper bar as heat sink gives us $119^{\circ} \mathrm{C} / \mathrm{s}$ as the average cooling rate in the heat-affected zone. Similarly, if the lower heat input rate when using the copper bar is applied, it gives us 444 ${ }^{\circ} \mathrm{C} / \mathrm{s}$ as the cooling rate in HAZ. Although using heat sink makes the weld profile narrower, it is not enough to prevent HAZ occurrence, so there is a need to use an external cooling device to get rid of heat-affected in the welded structures.

\subsection{Macro- and Microstructural Analysis}

The SEM image of the parent metal and the HAZ of the laser-welded sample can be found in Figure 8. Some dark, dark-bright and bright phases can be seen in various sizes, and a big difference in the size of the precipitates can be remarkably seen. It was revealed in Figure 8 a) that parent metal consisted of many smallsized and uniformly distributed precipitates, approximately $3-4 \mu \mathrm{m}$. These should be S' and S" particles. Presence of the fine and evenly distributed metastable precipitates enhances higher strength rates because of several reasons.

Firstly, they are coherent with the matrix and the interface between fine precipitates and other phases is sufficient to limit dislocation movement in each slipping plane through a decreased rate of interfacial free energy rate. Secondly, fine precipitates are distributed in the matrix uniformly, so the structure is more homogenous. It cannot be seen in any precipitate-depleted zone, which causes to reduce strength rate of the material based on the increased rate of inter-particle spacing.

Coarsened constituents, which were illustrated in Figure $8 \mathrm{~b}$ ), were coarsened from coherent particles due to the heat exposure during the laser welding process. Laser welding with $150 \mathrm{~kJ} / \mathrm{m}$ causes the cooling rate of 55 ${ }^{\circ} \mathrm{C} / \mathrm{s}$, which is enough to coarsen these fine-sized precipitates and these became $15-20 \mu \mathrm{m}$ and elongated. It means that the amount of the precipitates was 
decreased due to ease of migration of the atoms due to excessive heat exposure and coagulation of more solute atoms to form large-sized precipitates, which are equilibrium $\mathrm{S}$ phases in this case. It causes precipitatedepleted areas to occur and this decreases the mechanical properties. Coarsening and elongation of these precipitates cause to reduce the coherency, and they become incoherent with the aluminium matrix ( $\alpha$-phase).

The coarsening phenomenon can be clearly understood from Figure 8 that HAZ occurs because of coarsening of these main strengthening constituents (precipitates).

Achieving excellent mechanical properties by controlling the cooling rate is the primary purpose of this study. Because of this, parameters were varied to achieve higher cooling rate, which provides sufficient properties in HAZ. Application of heat input rate of $48 \mathrm{~kJ} / \mathrm{m}$ offers to reduce the duration of heat exposure and it can be figured out that less number of solute atoms collide to coagulate. The distribution of precipitates was also affected by lowering the heat input rate.
Distribution of precipitates is relatively uniform after application of heat input of $48 \mathrm{~kJ} / \mathrm{m}$. Still, higher heat input rate $(150 \mathrm{~kJ} / \mathrm{m})$ creates more precipitate-depleted areas than the application of heat input of $48 \mathrm{~kJ} / \mathrm{m}$. Figure $8 \mathrm{c})$ reveals that the size of precipitates is less $(10$ $-12 \mu \mathrm{m})$ than the alloy which was laser welded with 150 $\mathrm{kJ} / \mathrm{m}$. It means that using a lower heat input lowers the thermal degradation, but $192{ }^{\circ} \mathrm{C} / \mathrm{s}$ average cooling rate is not enough to suppress the harmful precipitate transition.

Changes in the weld characteristics in terms of appearance can be identified in Table 3. Lowering the heat input makes the weld zone smaller. Underfill was decreased and weld became hourglass shape by reducing the heat input and providing stable melt during the laser welding process. Furthermore, it can be easily recognised that using a copper bar increases the cooling rate and HAZ of laser-welded structures which were additionally cooled as the cooper bar became narrower. However, solidification shrinkage and macro-sized porosity occurred because of the higher cooling rate.
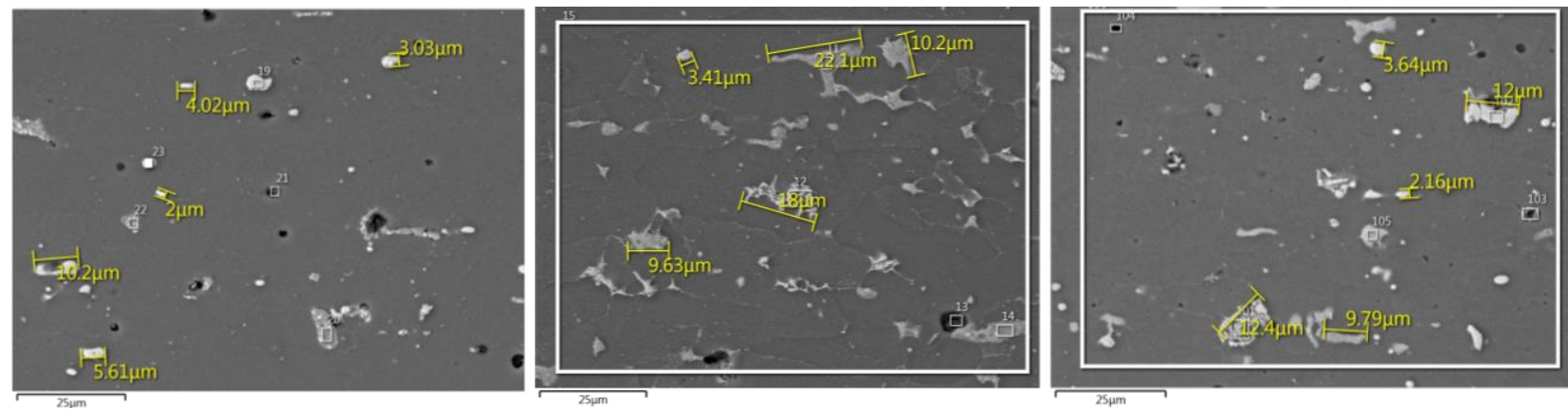

Fig 8. SEM images of AA 2024-T4 alloy, a) as received, b) laser welded with $150 \mathrm{~kJ} / \mathrm{m}$ and c) laser welded with $48 \mathrm{~kJ} / \mathrm{m}$.

\subsection{Hardness Measurements}

The difference between the copper backing bar in the jig and no copper bar in jig can be understood very well by checking the mechanical properties. It was revealed in Figure 9 that using the copper bar with lower heat input rates increases the material properties and makes the HAZ narrower. It was illustrated that FZ cooled faster through using the copper backing bar. Centre of FZ showed 109.1 HV with using the copper backing bar, but if no copper bar used, hardness in this area becomes $108.4 \mathrm{HV}$.

Notably, significant differences can be recognised in the area, which consists of columnar grains. As mentioned before, columnar grains occur because of slower cooling rate in this area. However, using a copper bar increases the cooling rate and, they become much smaller, so hardness rates become higher. The hardness of the areas which were not cooled by the copper backing bar are 102.4 HV and 101.3 HV. On the other hand, the hardness of the regions which were cooled by copper backing bar 107.2 HV and 104.4 HV.
Table 3. Macro-graphs of laser-welded structures.

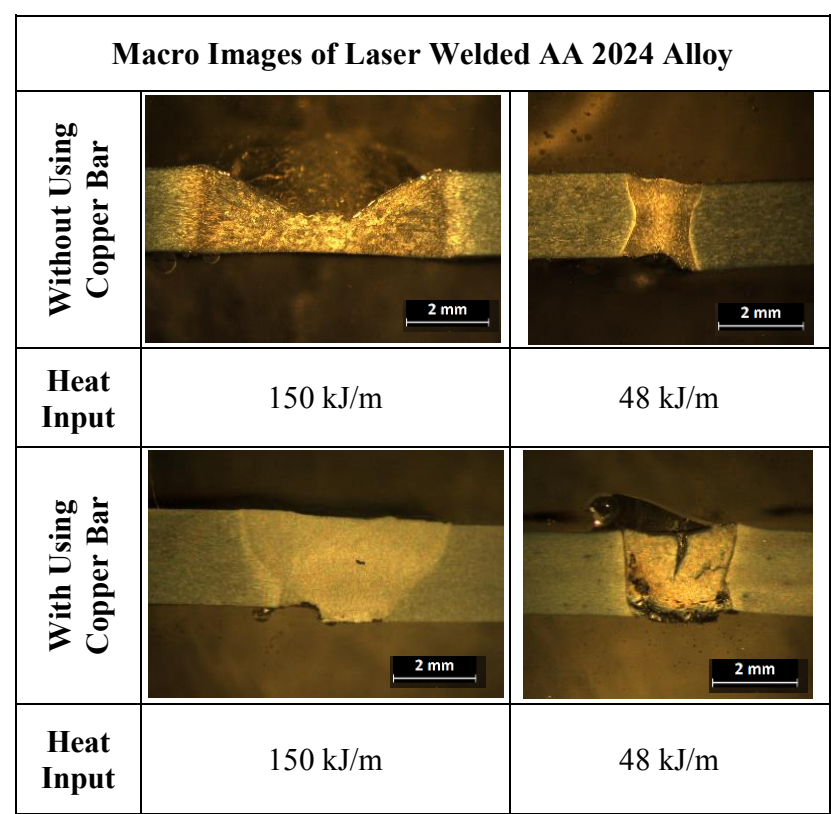




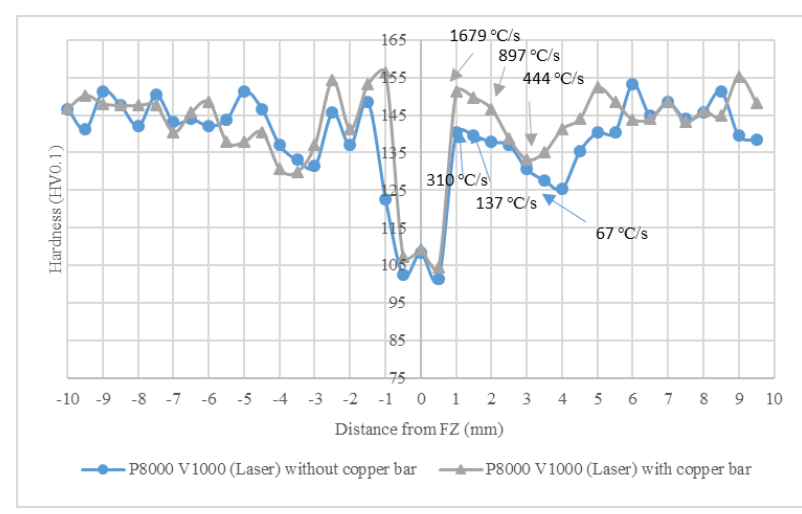

Fig 9. Hardness map of cooled/non-cooled laser welded samples.

The real difference can be seen in the solution strengthened zone. The hardness rates in this zone which were not cooled by the copper backing bar are $140.5 \mathrm{HV}$ in $1 \mathrm{~mm}, 139.6 \mathrm{HV}$ in $1.5 \mathrm{~mm}$ and $137.9 \mathrm{HV}$ in $2 \mathrm{~mm}$, but the hardness rates in this zone which were cooled by the copper backing bar are $151.2 \mathrm{HV}$ in $1 \mathrm{~mm}, 149.7 \mathrm{HV}$ in $1.5 \mathrm{~mm}$ and $146.7 \mathrm{HV}$ in $2 \mathrm{~mm}$. In this area, precipitations were dissolved in the matrix because of the exposed higher temperatures rate which can be seen as an orange line in Figure 6 . This temperature rate is not enough to melt this zone. However, it is enough to dissolve the precipitates. Then, a higher thermal gradient in this zone causes to re-precipitate in the grain boundaries in this area. As can be understood from the graph in Figure 9, HAZ locates next to the solution strengthened zone. Hardness in HAZ $(3 \mathrm{~mm})$ of laserwelded structure which was not cooled by a copper backing bar was around $130.7 \mathrm{HV}$, although hardness in HAZ of the copper cooled structure was around 133.2 $\mathrm{HV}$. Increasing the cooling rate from 192 to $444{ }^{\circ} \mathrm{C} / \mathrm{s}$ by using copper heat sink provides approximately $3 \mathrm{HV}$ increase in HAZ. The reason for this improvement can be clarified by that copper backing bar provides more rapid cooling, which has a positive effect on the evolution and distribution of precipitates in the aluminium matrix. More rapid cooling reduces the number of solute atoms migrating to collide and coagulate, as it can be seen in Figure $8 \mathrm{c}$ ). Finer and relatively uniformly distributed precipitates in the aluminium matrix, which are provided by increased cooling rate through using the copper backing bar, contribute to improving the weld profile in terms of micro-hardness rates. It is clearly recognised that using a copper backing bar increased the hardness in HAZ while decreasing the width of this area. However, it is not enough to mitigate HAZ by using copper heat sink as passive cooling.

Figure 9 also shows that the width of HAZ of laserwelded structure, which was not cooled by the copper backing bar, was approximately $4 \mathrm{~mm}$, although the width of HAZ of the copper cooled structure was approximately $3 \mathrm{~mm}$. It means that using the copper backing bar increases the cooling rate from $192{ }^{\circ} \mathrm{C} / \mathrm{s}$ to $444{ }^{\circ} \mathrm{C} / \mathrm{s}$ in this case and improves the weld profile due to decreasing the HAZ width.

\subsection{FEM Analysis}

If the data is established before is examined, it should be noted that using heat sink is not enough to prevent HAZ occurrence, although it seems that it makes the weld profile narrower. However, as the highest hardness rate locates at the distance of $1 \mathrm{~mm}$ from the centre of FZ, the amount of average cooling rate in this zone should be enough to create sufficient welded profile. Therefore, there is a need to use an external cooling device to mitigate $\mathrm{HAZ}$ in the welded structures.

FEM was used to simulate active cooling and to demonstrate what type of results active cooling can give. Realistically, a cooling rate of $1679{ }^{\circ} \mathrm{C} / \mathrm{s}$ can be achieved with the backing bar, but a sufficient and homogenous cooling rate cannot be obtained in the distant locations from FZ. It means that some areas suffer from the lower cooling rate, which results in softening in HAZ, which is caused by precipitate coarsening. For this reason, FEM is a handy tool to simulate active cooling and experienced thermal cycle which can be found in Figure 10. Peak temperature rates are decreased in the cooled structure and temperature rates dropped very rapidly, while laser welded and the non-cooled sample was experiencing 900 ${ }^{\circ} \mathrm{C}$. As it was shown in Figure 10, $0.35 \mathrm{~s}$ is enough to cool the laser-welded sample from peak temperature $\left(700^{\circ} \mathrm{C}\right)$ to room temperature.

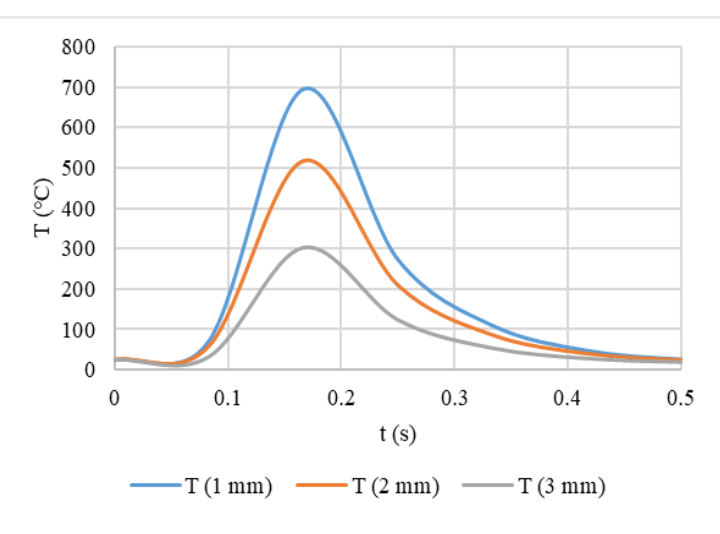

Fig 10. Thermal cycle of the actively cooled model.

Figure 11 shows that decreasing the surface temperature from room temperature to $5{ }^{\circ} \mathrm{C}$ during laser welding provides an increase in the cooling rate, and to mitigate HAZ through average cooling rate above $2000{ }^{\circ} \mathrm{C} / \mathrm{s}$ which is above the experimentally measured average cooling rate of $1679{ }^{\circ} \mathrm{C} / \mathrm{s}$ - which provided by passive cooling through using a copper heat sink. It means that lowering the surface temperature through active cooling provides a higher cooling rate and prevents HAZ softening. This type of external trailing cooling device enhances to suppress HAZ occurrence in high strength aluminium alloys after the laser welding process. It provides to reduce the need for post welding heat treatment (PWHT) which can provide to return pre-weld and as-received properties with the additional processes and extra costs. 


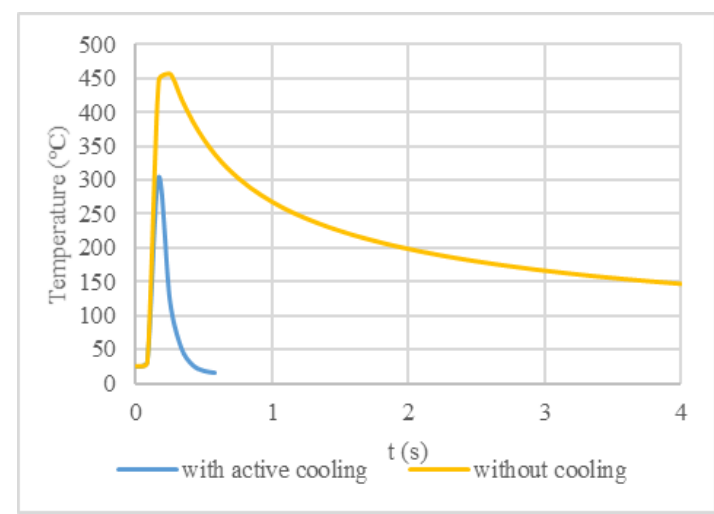

Fig 11. Comparison of the thermal cycle in the distance of 3 $\mathrm{mm}$ from the centre of FZ of the actively cooled model with the non-cooled model.

To summarise up, it must be worth bearing in mind that it is not possible to achieve enough cooling rate across HAZ of laser only processed structures. Therefore, some innovative design should be made for laser welding of high strength aluminium alloys, which consists of improved features in HAZ. FEM analysis of active cooling will likely be the right candidate for the prevention of HAZ softening.

\section{Conclusion}

In this work, an initial correlation between welding conditions, thermal cycle and the resulting microstructural response has been studied.

- Higher heat input causes a decreased rate of cooling rate.

- Heat release from weld zone causes precipitates to get coarsened in HAZ and this coarsening of precipitates decreases mechanical properties. Thermal cycle and cooling rate of welding have a critical influence on the mechanical properties due to negative precipitate evolution.

- $\quad$ Passive cooling through using copper bar increases the cooling rate. Experiments showed that in HAZ copper bar increased cooling rate from $192{ }^{\circ} \mathrm{C} / \mathrm{s}$ to $444{ }^{\circ} \mathrm{C} / \mathrm{s}$, but this improvement is not enough to prevent $\mathrm{HAZ}$ occurrence.

- Solid solution strengthened area of the laser-welded sample shows higher hardness rate then, because this zone experienced a higher cooling rate (1679 ${ }^{\circ} \mathrm{C} / \mathrm{s}$ ) which suppressed the precipitate coarsening.

- It has been proven by FEM modelling that using additional external active cooling device/equipment will be an excellent solution to provide rapid cooling with the cooling rate above $2000{ }^{\circ} \mathrm{C} / \mathrm{s}$ for prevention of softening in initial zones. It can also increase the productivity of this process by improving the process characteristics with a novel design.

\section{References}

Ahn, J., Chen, L., He, E., Dear, J. P. and Davies, C. M. (2018) 'Optimisation of Process Parameters and Weld Shape of High Power Yb-Fibre Laser Welded 2024-T3 Aluminium Alloy', Journal of Manufacturing Processes, 34(April), pp. 70-85. DOI: 10.1016/j.jmapro.2018.05.028.

Alshaer, A. W., Li, L. and Mistry, A. (2017) 'Effect of filler wire properties on porosity formation in laser welding of AC-170PX aluminium alloy for lightweight automotive component manufacture', Proceedings of the Institution of Mechanical Engineers, Part B: Journal of Engineering Manufacture, 231(6), pp. 994-1006. DOI: 10.1177/0954405415578584.

Ambriz, R. R. and Jaramillo, D. (2014) 'Mechanical Behavior of Precipitation Hardened Aluminum Alloys Welds', in Monteiro, W. A. (ed.) Light Metal Alloys Applications. Intech Open Access, pp. 35-59. doi: $10.5772 / 58418$.

Andersen, S. J., Marioara, C. D., Friis, J., Wenner, S. and Holmestad, R. (2018) 'Precipitates in Aluminium Alloys', Advances in Physics: $X$, 3(1), pp. 790-813. DOI: 10.1080/23746149.2018.1479984.

Arora, K. S., Pandey, S., Schaper, M. and Kumar, R. (2010) 'Microstructure Evolution during Friction Stir Welding of Aluminum Alloy AA2219', Journal of Materials Science and Technology, 26(8), pp. 747-753. DOI: 10.1016/S1005-0302(10)60118-1.

Fridlyander, I. N., Sister, V. G., Grushko, O. E., Berstenev, V. V., Sheveleva, L. M. and Ivanova, L. A. (2002) 'Aluminum alloys: Promising materials in the automotive industry', Metal Science and Heat Treatment, 44(9-10), pp. 365-370. DOI: 10.1023/A:1021901715578.

Hong, K. M. and Shin, Y. C. (2017) 'Prospects of laser welding technology in the automotive industry: A review', Journal of Materials Processing Technology. Elsevier B.V., 245, pp. 46-69. DOI: 10.1016/j.jmatprotec.2017.02.008.

Jordan, A. (2016) Microstructure Characterisation and Corrosion Properties of Two Recycled Aluminium Alloys AA5050 and AA5011. PhD Thesis. The University of Manchester.

Miller, W. S., Zhuang, L., Bottema, J., Wittebrood, A. J., De Smet, P., Haszler, A. and Vieregge, A. (2000) 'Recent development in aluminium alloys for the automotive industry', Materials Science and Engineering: A, 280(1), pp. 37-49. DOI: 10.1016/S09215093(99)00653-X.

Mishra, R. S. and Sidhar, H. (2017) 'FSW of Al - $\mathrm{Cu}$ and $\mathrm{Al}-\mathrm{Cu}-$ Mg Alloys', in Gifford, C. (ed.) Friction Stir Welding of $2 X X X$ Aluminum Alloys Including Al - Li Alloys. Oxford, UK: ButterworthHeinemann, pp. 47-77. DOI: 10.1016/b978-0-12-805368-3.00004-2.

Nascente, P. A. P., Bolfarini, C., Benassi, C. L., Alcântara, N. G. and Santos, J. F. (2002) 'Surface and Microstructural Characterisation of Laser Beam Welds in an Aluminum Alloy', Journal of Vacuum Science \& Technology A: Vacuum, Surfaces, and Films, 20(4), pp. 1416-1419. DOI: 10.1116/1.1487868.

Niu, L. Q., Li, X.-Y., Zhang, L., Liang, X.-B. and Li, M. (2017) 'Correlation between Microstructure and Mechanical Properties of 2219-T8 Aluminum Alloy Joints by VPTIG Welding', Acta Metallurgica Sinica (English Letters), 30(5), pp. 438-446. DOI: 10.1007/s40195-016-0516-9.

Oguz, B. (1990) 'Aluminium Alloys', in Welding of the Non-Ferrous Metals. Oerlikon.

Sakurai, T. (2008) 'The Latest Trends in Aluminum Alloy Sheets for Automotive Body Panels', KOBELCO Technology Review, 28, pp. 2228 .

Sánchez-Amaya, J. M., Boukha, Z., Amaya-Vázquez, M. R. and Botana, F. J. (2012) 'Weldability of Aluminum Alloys with HighPower Diode Laser', Welding Journal, pp. 155s-161s. Available at: http://files.aws.org/wj/supplement/WJ_2012_05_s155.pdf (Accessed: 2 May 2019). 
Tsirkas, S. A., Papanikos, P. and Kermanidis, T. (2003) 'Numerical simulation of the laser welding process in butt-joint specimens', Journal of Materials Processing Technology, 134(1), pp. 59-69. DOI: 10.1016/S0924-0136(02)00921-4.

Zervaki, A. D. and Haidemenopoulos, G. N. (2007) 'Computational kinetics simulation of the dissolution and coarsening in the HAZ during laser welding of 6061-T6 Al-alloy', Welding Journal, 86(8), pp. $211 \mathrm{~s}-221 \mathrm{~s}$

Zhang, L., Li, X., Nie, Z., Huang, H. and Niu, L. (2016) 'Comparison of microstructure and mechanical properties of TIG and laser welding joints of a new Al-Zn-Mg-Cu alloy', Materials and Design. Elsevier Ltd, 92, pp. 880-887. DOI: 10.1016/j.matdes.2015.12.117.

Zhang, L., Li, X., Nie, Z., Huang, H. and Sun, J. (2015)

'Microstructure and Mechanical Properties of a New Al-Zn-Mg-Cu

Alloy Joints Welded by Laser Beam', Materials \& Design, 83, pp. 451-458. DOI: 10.1016/j.matdes.2015.06.070.

Zhao, N., Yang, Y., Han, M., Luo, X., Feng, G. and Zhang, R. (2012) 'Finite element analysis of pressure on 2024 aluminum alloy created during restricting expansion-deformation heat-treatment', Transactions of Nonferrous Metals Society of China (English Edition), 22(9), pp. 2226-2232. DOI: 10.1016/S1003-6326(11)61453-2. 